\title{
Gerenciamento de riscos na prática ortodôntica - como se proteger de eventuais problemas legais
}

\author{
Ricardo Machado Cruz*, Carla Pádua Andrade Chaves Cruz**
}

\begin{abstract}
Resumo
Introdução: A relação profissional-paciente na área de Ortodontia e Ortopedia facial é bastante desgastante face à longa duração dos tratamentos e, por causa disso, muitas vezes essa relação pode se deteriorar trazendo prejuízos a ambas as partes. Objetivo: Este trabalho visa informar o leitor, em linguagem acessível, sobre os principais problemas jurídicos que podem envolver o ortodontista em sua prática profissional, nas esferas cíveis, criminais e trabalhistas, bem como dos Conselhos Regionais de Odontologia. Metodologia: Traça um perfil da atividade profissional em Ortodontia, analisa deveres e direitos do profissional e do paciente e estabelece alguns conceitos de gerenciamento de riscos a serem incorporados à clínica diária. Resultado e Conclusão: Além de trabalhar bem tecnicamente e com bom embasamento científico, o ortodontista atual deve saber como se prevenir de eventuais problemas legais. Este trabalho poderá servir como ferramenta de consulta para o estabelecimento de uma nova rotina clínica, administrativa e de relacionamento que seja mais segura do ponto de vista jurídico.
\end{abstract}

Palavras-chave: Ortodontia. Problemas legais. Gerenciamento de riscos.

\section{INTRODUÇÃO}

A Ortodontia, com a Prótese e a Implantodontia têm sido as áreas da Odontologia com maior número de processos na Justiça. Tal fato se dá por várias razões: os procedimentos são mais onerosos, os tratamentos, geralmente, são mais demorados e envolvem conceitos de estética, que são muito subjetivos, todas possuem procedimentos às vezes controversos e, finalmente, pelo fato de haver grande número de profissionais trabalhando sem treinamento adequado.

A relação profissional-paciente sempre se baseou na confiança e no respeito mútuo. Porém, nos últimos anos, tem havido uma mudança no rela- cionamento interpessoal. Todos os registros feitos entre as partes, que sempre foram verbais passam a ser escritos. Essa mudança de atitude começou a ser observada principalmente após a promulgação do Código de Defesa do Consumidor (Lei 8078/90), apesar do antigo código civil já prever a responsabilidade civil profissional.

A situação que começa a ser vivenciada pelos ortodontistas brasileiros já é bastante conhecida dos colegas norte-americanos. Nos Estados Unidos existe uma verdadeira "fábrica de processos", com número cada vez maior de advogados especializados em processar profissionais de saúde. Acreditase que, num futuro próximo, todo ortodontista

* Mestre em Ortodontia e Ortopedia Facial (FO- UFRJ). Doutor em Biologia Animal-Genética (UnB). Professor Adjunto de Ortodontia (UNIP- Brasília).

** Advogada OAB-DF 9698. Especialista em Direito Europeu (Univ. Católica de Lisboa). 
americano estará envolvido em, pelo menos, uma ação de responsabilidade profissional ${ }^{8}$. Talvez em função disso haja lá uma extensa literatura a respeito dos cuidados que o profissional de saúde, mais especificamente o ortodontista, deve tomar para que a relação com o paciente não se deteriore. No Brasil, os trabalhos científicos sobre o tema são raros, mas vêm aumentando face à nova realidade. Cada vez mais se faz necessária a realização de novas pesquisas, uma vez que a sociedade brasileira tem características próprias e leis peculiares. Dos trabalhos existentes, alguns comparam o comportamento profissional dos ortodontistas brasileiros e americanos no que diz respeito aos aspectos éticos e legais, levando em consideração as diferentes leis e conscientização da população ${ }^{5}$. Mas por que comparar duas sociedades tão distintas? Acredita-se que a possibilidade de se usar a experiência adquirida por profissionais que atuam em sociedades mais desenvolvidas é uma opção incontestável para permitir que se possa evitar problemas já identificados ${ }^{1}$.

No rol de problemas que podem envolver o ortodontista, estão os problemas éticos, pessoais (relacionamento profissional-paciente) e jurídicos.

\section{PROBLEMAS ÉTICOS}

A ética baseia-se em valores morais e sociais. Ética não se ensina, se vive. Ela precisa estar dentro de nós. Não se deve confundir ética com corporativismo, pois enquanto o corporativismo defende os direitos de uma corporação, a ética defende os direitos de todos, incluindo aí os dos pacientes. $\mathrm{Na}$ esfera da ética, três grandes problemas podem envolver o ortodontista: a concorrência desleal, a propaganda inadequada (que além de ser um problema ético é também um problema legal) e a difamação de colegas - comentários maldosos com intenção de melhorar a auto-imagem do profissional que podem precipitar ações legais. Em relação à concorrência desleal muito se tem falado. Talvez em razão do agravamento da situação econômica que faz com que alguns colegas partam para um comportamento perigoso de redução dos honorários. Se o profissional anuncia a gratuidade inicial do tratamento, está configurada a concorrência desleal, cabendo representação junto ao órgão fiscalizador da profissão ${ }^{2}$. Além disso, o profissional que não cobra o valor inicial para o tratamento ortodôntico está, ele próprio, desvalorizando o seu trabalho intelectual ${ }^{2}$. No que diz respeito à difamação de colegas, o caso pode ir para os Conselhos Regionais ou mesmo para a Justiça comum. O profissional deve tomar muito cuidado ao emitir sua opinião a respeito de trabalhos executados por colegas, pois segundo o Prof. Moacyr da Silva, "consultório não é Tribunal de ética", ou seja, não é local para julgar trabalhos de colegas, pois não sabemos em que condições foram feitos os mesmos. Nos Estados Unidos, cerca de $40 \%$ dos processos contra ortodontistas são iniciados como resultado de uma segunda opinião criticando a terapia ${ }^{9}$. Se, por qualquer motivo, o profissional for chamado a emitir uma segunda opinião sobre um determinado caso, deve lembrar sempre que essa opinião pode gerar uma ação litigiosa envolvendo o paciente, o clínico responsável pelo caso e o profissional que emitiu a segunda opinião. Por isso algumas regras devem ser observadas, tais como fazer cuidadosa análise do caso, solicitar documentação completa (caso necessário) e contatar o clínico anterior. Em relação a esse último ponto, alguns autores recomendam que só vale a pena contatar o clínico anterior se o mesmo for um especialista em Ortodontia e Ortopedia facial ${ }^{10}$.

\section{PROBLEMAS PESSOAIS (RELACIONAMEN- TO PROFISSIONAL-PACIENTE)}

Outra área na qual o ortodontista poderá ter problemas, diz respeito ao relacionamento com o paciente. Para que o profissional não tenha problemas nesse campo pessoal, sugere-se que mantenha sempre uma relação de amizade com os pacientes e seus responsáveis, que mantenha uma equipe de funcionários bem treinada para lidar com cortesia com os pacientes, e que tenha uma rotina diária 
bem organizada, na qual procure atender seus pacientes sempre dentro dos horários marcados. Atrasos são inevitáveis, mas quando houver procurar sempre se desculpar com o paciente, fazendo-o acreditar que sejam esporádicos. Outra atitude que ajuda a preservar a relação de cordialidade entre profissional e paciente é manter sempre um registro escrito de tudo que é acordado entre as partes. Da mesma maneira, todas as orientações e esclarecimentos devem ser por escrito e redigidos de maneira clara e precisa.

Para que os cirurgiões-dentistas, mais especificamente os ortodontistas, possam se resguardar de processos na justiça, vale mais a pena investir em qualidade de atendimento e evitar desentendimentos menores com os pacientes. Para isso é interessante saber quais as principais reclamações feitas pelos pacientes na justiça. São elas:

- "O dentista não deu a devida atenção ao paciente": mais comum em clínicas grandes, com muito movimento, onde às vezes o profissional perde o controle da situação de cada paciente.

- Assédios sexuais (em qualquer idade): embora não haja lei específica nem jurisprudência, o assédio sexual pode comprometer a reputação do profissional e levá-lo à corte. Existem medidas preventivas que podem ser tomadas para evitar o risco, principalmente naqueles casos onde o/a paciente age de má fé. Essas medidas seriam, por exemplo: trabalhar em consultórios com portas de vidro, trabalhar de porta aberta ou na presença da mãe, pai ou da auxiliar.

- "O dentista atrasa muito": o profissional deve organizar sua agenda de maneira que os atrasos sejam esporádicos, somente nos casos inevitáveis. E quando acontecerem seria cordial pedir desculpas ao paciente. Muitos pacientes reclamam que não recebem nenhuma satisfação por parte do profissional ou de sua equipe.

- "Não gostei do resultado": esse problema é mais sério, pois mostra uma falta de diálogo entre profissional e paciente que pode levar a um desentendimento ao final do tratamento. A sugestão é sempre ouvir a queixa do paciente, ser o mais honesto possivel, não esconder o prognóstico do tratamento, explicar ao paciente os procedimentos que estão sendo tomados e mostrar as eventuais limitações de um determinado tratamento. $\mathrm{O}$ grande risco do Ortodontista é que os juristas têm visto a Ortodontia como ciência de fim ou de resultados e na verdade trata-se de ciência de meio, na qual o profissional usa todos os meios possíveis para tentar chegar ao resultado.

- Discussão por pagamentos de honorários: os detalhes financeiros e as regras devem ser tratados antes de iniciar o tratamento e devem ser registrados por escrito, com assinatura do profissional e do paciente. Qualquer alteração deve ser feita por escrito e deve ter também a assinatura do paciente.

- "Não quis me atender": Tem acontecido com freqüência, em casos de pacientes portadores de $\mathrm{HIV}^{+}$, por exemplo. Deve ser lembrado que o profissional não é obrigado a atender todos os pacientes que lhe procuram, se esse tratamento for eletivo. Se for urgência (houver dor), existe uma obrigação ética e moral.

\section{PROBLEMAS JURÍDICOS}

Os problemas de ordem jurídica podem acontecer em diversas esferas: justiça trabalhista, PRO$\mathrm{CON}$, juizado especial cível, justiça comum (varas cíveis), juizado especial criminal, justiça criminal (varas criminais) e Ministério Público.

a) Justiça trabalhista: $\mathrm{Na}$ justiça trabalhista, o maior risco para o ortodontista é ser réu de algum processo movido por algum funcionário. Esses problemas geralmente ocorrem em razão de contratos trabalhistas mal feitos. Deve-se lembrar que todos os funcionários devem ser registrados e que há pisos salariais diferentes para cada categoria. $\mathrm{O}$ segredo para evitar aborrecimentos nessa esfera é ter um bom e confiável contador.

b) PROCON: O PROCON é um órgão do poder executivo, que cuida para que o Código de Defesa do Consumidor (Lei 8.078 de 11/09/90) seja obedecido. Quando se pensa em atendimento 
odontológico como serviço prestado e em paciente como consumidor, estabelece-se uma relação de consumo, que pode ser ditada pelo Código de Defesa do Consumidor. Quando um paciente aciona o PROCON, em função de algum desentendimento entre ele e o profissional, existem somente 3 tipos de acordo que podem ser feitos: devolução do dinheiro, retratamento pelo próprio profissional ou retratamento por um colega. Vale dizer que o PROCON não prevê nenhum tipo de indenização em dinheiro e existe um princípio, que é conhecido no Direito como inversão do ônus da prova, ou seja, o paciente não tem que provar nada, o profissional é que tem que provar que não deu causa ao resultado. O Código de Defesa do Consumidor é bastante amplo, mas em relação à odontologia, um dos artigos mais importantes é o artigo 14, transcrito abaixo:

- Art. 14 - "o fornecedor de serviços responde, independentemente da existência de culpa, pela reparação dos danos causados aos consumidores por defeitos relativos à prestação dos serviços, bem como por informações insuficientes ou inadequadas sobre sua fruição e riscos".

- Par. 40 "A responsabilidade pessoal dos profissionais liberais será apurada mediante a verificação da culpa".

Em relação à prescrição numa relação de consumo, o CDC diz o seguinte:

- Art. 27 - "Prescreve em cinco anos a pretensão à reparação pelos danos causados por fato do produto ou do serviço..., iniciando-se a contagem do prazo a partir do conhecimento do dano e de sua autoria".

c) Juizado Especial Cível: Para entrar no Juizado Especial Cível (Juizado de Pequenas Causas), o paciente não precisa ter advogado, se o valor da causa for de até 20 salários mínimos. Para causas acima de 20 salários mínimos é necessário constituir advogado. Vale lembrar que para entrar nos Juizados Especiais Cíveis, o valor total da causa não pode ultrapassar 40 salários mínimos. A jurisprudência também não tem aceitado causas com- plexas, que exijam perícia, devido à dificuldade de avaliar os danos.

d) Justiça Cível: Se o valor da causa ultrapassar 40 salários mínimos, o paciente poderá entrar na Justiça Comum (Varas Cíveis). As estatísticas indicam aumento no número de processos de negligência em Ortodontia no âmbito da justiça comum. Ao contrário do PROCON, na Justiça comum o princípio que vale é do ônus da alegação, ou seja, quem alega deve provar (no caso o paciente). Quem perde deve pagar as custas do processo e os honorários dos advogados. Há cada vez mais um número crescente de processos contra dentistas. O valor final dessas ações é imprevisível, pois o paciente pode incluir todos os danos patrimoniais comprováveis, tais como: locomoções, exames, lucros cessantes, etc, e o juiz arbitra os danos morais. Caso o Juiz precise obter mais informações sobre um processo poderá nomear um perito que avaliará o caso e emitirá seu parecer. O perito geralmente é um profissional respeitado na sua área de atuação. Para que ele também se resguarde terá que ser cuidadoso, estudar bem a documentação, os registros, procurando ouvir o colega processado antes de emitir seu laudo. O perito terá que responder basicamente três perguntas ao escrever seu laudo: Aquele procedimento atende às normas da Odontologia? Resolve os problemas do paciente? Não cria novos problemas para o paciente?

Em relação às indenizações, o Código Civil prevê em vários de seus artigos, as normas a serem seguidas:

- Art. 927 - da obrigação de indenizar: "Aquele que, por ato ilícito (arts. 186 e 187), causar dano a outrem, fica obrigado a repará-lo".

Parágrafo único. "Haverá obrigação de reparar o dano, independentemente de culpa, nos casos especificados em lei, ou quando a atividade normalmente desenvolvida pelo autor do dano implicar, por sua natureza, risco para os direitos de outrem".

- Art. 949 - "No caso de lesão ou outra ofensa à saúde, o ofensor indenizará o ofendido das despe- 
sas do tratamento e dos lucros cessantes até ao fim da convalescença, além de algum outro prejuízo que o ofendido prove haver sofrido".

- Art. 950 - "Se da ofensa resultar defeito pelo qual o ofendido não possa exercer o seu ofício ou profissão, ou se lhe diminua a capacidade de traba1ho, a indenização, além das despesas do tratamento e lucros cessantes até o fim da convalescença, incluirá pensão correspondente à importância do trabalho para que se inabilitou, ou da depreciação que ele sofreu".indenizações

- Art. 951 - "O disposto nos arts. 948, 949 e 950 aplica-se ainda no caso de indenização devida por aquele que, no exercício da atividade profissional, por negligência, imprudência ou imperícia, causar a morte do paciente, agravar-lhe o mal, causar-lhe lesão, ou inabilitá-lo para o trabalho".

Uma das questões que gera mais dúvidas entre os profissionais e mesmo entre os juristas diz respeito à prescrição dos prazos para as ações na justiça. Na Justiça Comum, o novo Código Civil traz as seguintes informações:

- Art. 205 - "A prescrição ocorre em dez anos, quando a lei não lhe haja fixado prazo menor".

- Art. 206: Prescreve:

$\S 3$ - Em três anos:

V - a pretensão de reparação civil".

e) Justiça Criminal: Se houver no caso algum tipo de lesão corporal e/ou morte, paciente ou seus familiares poderão entrar com um processo na justiça criminal (varas criminais). Felizmente ainda existem poucos processos na justiça criminal envolvendo a Odontologia. Existem quatro diferentes tipos de lesões corporais: leve, grave, gravíssima e gravíssima seguida de morte. No caso da Odontologia, e mais especificamente da Ortodontia e Ortopedia facial, a maior preocupação tem sido a perda de dentes em função de extrações dentárias sem respaldo científico e de reabsorções radiculares extensas. Por isso, sempre que o profissional precisar solicitar extrações de dentes permanentes com finalidade ortodôntica, deve fazê-lo por escrito somente após esclarecimento, principalmente se o paciente for menor de idade. Além disso, o cirurgião que for escolhido pelo paciente para realizar as extrações não tem obrigação de concordar com a solicitação, e poderá não fazêlas caso não ache conveniente. Se essas medidas forem tomadas, o profissional poderá se isentar do processo civil e/ou criminal. Numa sociedade que cada vez mais valoriza a autonomia dos indivíduos, principalmente das crianças, recomenda-se que em casos de extrações em menores, mesmo que os pais consintam, se o menor se opuser, a atitude mais prudente seria o profissional registrar o fato no prontuário e instruir pais e paciente a retornarem ao consultório somente após terem chegado a um consenso.

Na esfera penal, o artigo 103 do Código Penal menciona que a decadência do direito de queixa ou de representação se dá dentro do prazo de seis meses, contado do dia em que se sabe quem é o autor do crime, ou do dia em que se esgota o prazo para oferecimento da denúncia.

f) Ministério Público: Outra opção que está disponível para o paciente poder reclamar seus direitos é entrar com um processo no Ministério Público. Dentro desses órgãos existem várias Promotorias capazes de acolher a solicitação da população no que se refere a queixas contra um atendimento na área odontológica. As mais usadas são o PRODECON (Promotoria de Defesa do Consumidor) e PRÓ-VIDA (Promotoria de Defesa dos Usuários dos Serviços de Saúde). Esta última foi criada há pouco tempo no Distrito Federal e vem tendo uma procura bastante grande, sendo um excelente fórum para os acertos jurídicos entre o profissional e o paciente. Essa idéia já vem se espalhando pelo país e outras unidades da federação já contam com serviço semelhante. No Pró-Vida do Ministério Público do Distrito Federal e Territórios já foram analisados mais de 300 casos. A maior parte dos desentendimentos foi devido à falta de comunicação adequada entre as partes. Trata-se da melhor opção para os acordos, pois prevê uma 
Câmara Técnica de Conciliação, onde as partes vão discutir os acertos necessários, mediados por um Promotor com formação e conhecimento na área de saúde. Este Promotor, após ouvir as partes, analisará as informações prestadas por ambas as partes e determinará a forma de reparo dos danos, fixando também o valor da indenização. $\mathrm{O}$ montante dessa indenização geralmente não é tão alto quanto os valores conseguidos na Justiça comum (Varas Cíveis). Vale também ressaltar que, segundo a Lei 9.099/95, todos os acordos realizados na Promotoria encerram as discussões sobre o caso, que é arquivado, não cabendo reclamações posteriores na Justiça comum a nenhuma das partes. Caso não haja acordo, o Promotor pode remeter o caso para a Justiça comum.

\section{SEGUROS DE RESPONSABILIDADE CIVIL}

Diante de tantas possibilidades de ação na justiça, seria então interessante que o profissional de saúde se resguardasse fazendo um seguro de responsabilidade civil? Seria esse seguro a solução para as querelas jurídicas ou seria mais um problema? Algumas pesquisas feitas nos Estados Unidos provam que o profissional não está totalmente resguardado. Um desses trabalhos avaliou uma amostra de ortodontistas americanos que tinham seguro, mas que nunca tinham sido envolvidos em ações judiciais. Foi mostrado que ninguém lia os contratos e poucos faziam regularmente uma revisão dos níveis de cobertura ou se importavam em saber como a seguradora cuidaria de seus interesses em caso de litígio. Nos Estados Unidos, os advogados das seguradoras raramente trazem notícias para o profissional, e os ortodontistas nunca são chamados para ajudar a preparar a defesa, sendo raramente consultados sobre as ofertas de acordo $^{6}$. No Brasil, os seguros de responsabilidade civil para cirurgiões-dentistas vêm se popularizando cada vez mais, oferecendo coberturas de até $\mathrm{R} \$$ 150.000,00 com mensalidades irrisórias, através dos seguros em grupo. Porém, os valores das causas na Justiça comum que afetam os cirurgiões-den- tistas têm sido mais altos que a cobertura oferecida, de maneira que esses seguros podem não ser a solução definitiva para os problemas jurídicos. Há um risco grande de o profissional relaxar, não tomando os devidos cuidados e acabar tendo mais prejuízos. Por isso, recomenda-se que os cirurgiões dentistas façam seguro de responsabilidade civil, mas não se descuidem das medidas de segurança para evitar problemas legais.

\section{RESPONSABILIDADE SOLIDÁRIA}

Outro ponto que deve ser mencionado diz respeito à responsabilidade solidária. $\mathrm{O}$ responsável técnico de uma clínica responde solidariamente por outro dentista da clínica para efeitos de indenização civil. O Convênio tem responsabilidade solidária pelos seus dentistas conveniados, e o Estado responde solidariamente pelos dentistas servidores públicos. Essas informações estão no novo Código Civil, nos seguintes artigos:

- Art. 932. "São também responsáveis pela reparação civil:"

...

III - "o empregador ou comitente, por seus empregados, serviçais e prepostos, no exercício do trabalho que lhes competir, ou em razão dele";

- Art. 942. "Os bens do responsável pela ofensa ou violação do direito de outrem ficam sujeitos à reparação do dano causado; e, se a ofensa tiver mais de um autor, todos responderão solidariamente pela reparação".

- Parágrafo único. "São solidariamente responsáveis com os autores os co-autores e as pessoas designadas no art. 932".

Também existe uma súmula do Supremo Tribunal Federal, que diz o seguinte:

- Sum. 341 - "É presumida a culpa do patrão ou comitente pelo ato culposo do empregado ou preposto".

E no Código de Defesa do Consumidor:

- Art. 8, 20 e 25:

- "Administradoras de planos de saúde, profissionais de saúde e estabelecimentos conveniados 
respondem solidariamente por qualquer dano provocado por atendimento deficiente".

- Cabe ação pleiteando indenização do profissional (médico ou dentista), da empresa (plano de saúde ou convênio) e do estabelecimento (clínica ou hospital).

- Além deste expediente também cabe denúncia do profissional ao Conselho Regional, que analisará os aspectos éticos".

$\mathrm{Na}$ justiça criminal não existe responsabilidade solidária.

\section{ASPECTOS CLÍNICOS ORTODÔNTICOS}

Seria interessante relacionar os principais aspectos clínicos rotineiros ligados à Ortodontia e Ortopedia Facial, que têm sido a causa de litígios na justiça brasileira e norte-americana ${ }^{7,12}$. São eles:

a) Reabsorção radicular: é considerada uma das principais causas de litígio nos Estados Unidos. Porém, algumas medidas podem ser tomadas para evitar maiores problemas, tais como: sempre esclarecer previamente o paciente (por escrito) acerca dos riscos inerentes ao tratamento ortodôntico, e dentro desses riscos se encaixam as reabsorções radiculares. Fazer uma boa anamnese e solicitar tomadas radiográficas de controle. Na ocorrência de reabsorção radicular sugere-se fazer um registro por escrito dos principais fatores e providências a serem tomadas, e sempre que precisar embasar-se na literatura científica.

b) Problemas periodontais: também são responsáveis por um alto índice de processos na justiça. São problemas que exigem uma elevada cooperação do paciente, o que muitas vezes não é conseguido. O Ortodontista deve sempre exigir um acompanhamento periodontal inicial e freqüente, e manter registro das principais ocorrências (por exemplo, através de sondagens periodontais). A responsabilidade deve ser dividida com o clínico geral e com o periodontista. Uma especial atenção deve ser dada aos adultos, que têm maior propensão à mobilidade dentária e à perda óssea. c) Dentes inclusos e impactados: Um registro preliminar deve ser preparado com a localização do dente e a probabilidade de sucesso do tracionamento. Deve-se também determinar os riscos de uma extração em conjunto com o cirurgião. A decisão deve ser tomada em conjunto e assinada pelo paciente, para depois ser arquivada.

d) Disfunções de ATM: Área complexa de atuação com grande número de processos contra Ortodontistas. As principais causas de litígio são: falha em reconhecer ou identificar a Disfunção Têmporo-Mandibular e em responder adequadamente às queixas do paciente, e falha em admitir as limitações do tratamento ortodôntico. Os cuidados a serem tomados incluem exame clínico detalhado, história clínica de tratamentos prévios, alerta sobre as causas multifatoriais e as limitações do tratamento ortodôntico.

e) Doenças infecto-contagiosas: A negligência nos cuidados relativos ao controle de infecção pode levar a implicações legais. A Justiça vê que as medidas para esse controle estão ao alcance de todos os profissionais e de seus auxiliares, que devem colocá-las em prática, para sua própria proteção e de seus pacientes. É um terreno fértil para a litigância de má-fé, e na justiça o profissional terá que provar que agiu com perfeição. Os que não conseguirem provar serão responsabilizados. $\mathrm{Na}$ biossegurança existe sempre um risco de contaminação evitável e um inevitável. O progresso científico reduz cada vez mais o risco evitável. O não cumprimento das regras de biossegurança indica negligência, o que pode ter repercussões éticas, administrativas, legais e cíveis. Para evitar problemas dessa ordem, recomenda-se que o profissional mantenha uma equipe bem treinada e supervisionada, através de cursos e palestras, mostre e explique aos pacientes os cuidados que estão sendo tomados na questão de biossegurança, incluindo aí visitas à central de processamento e esterilização, não produzir provas de condições e atitudes inadequadas para ter como provar em juízo que agiu corretamente (as rotinas estabelecidas devem 
ser anotadas seqüencialmente e deve-se arquivar todas as notas fiscais de equipamentos e materiais de consumo voltados para a biossegurança) ${ }^{3}$.

e) Aparência facial: Alterações faciais que desagradem ao paciente podem levar a processos na justiça. Para evitá-los, devem-se conhecer as expectativas do paciente e explicar as alterações faciais decorrentes do crescimento e desenvolvimento e do tratamento ortodôntico proposto, pois uma orientação correta elimina desapontamentos e diminui as chances de litígios.

f) Cuidados na finalização: Somente uma pequena parcela de profissionais da Ortodontia faz uma lista de checagem antes da remoção do aparelho. Elas são de suma importância para melhorar a qualidade dos resultados. Também nesse caso é muito importante ouvir a opinião do paciente; isso aumenta a credibilidade profissional e reforça a participação do paciente, dividindo as responsabilidades.

\section{CONCEITOS DE GERENCIAMENTO DE RISCOS A SEREM ADOTADOS NA CLÍNICA}

a) Prontuário odontológico: tem que ser claro, preciso e bem organizado, deve conter a identificação do paciente e os dados da anamnese. O registro escrito da anamnese deve ser sempre realizado. Ela pode ser respondida inicialmente pelo paciente com respostas fechadas: "sim" e "não" e depois aprofundado pelo profissional. Deve ser datado e assinado pelo paciente (maior de idade) ou pelo responsável (menores).

$\mathrm{Na}$ ficha clínica devem ser feitas as devidas anotações, lembrando-se que todos os procedimentos realizados devem ser anotados (inclusive faltas ou atrasos, higiene oral, falta de cooperação no uso do aparelho extra-oral, acessórios soltos, cáries, restaurações quebradas etc). Ao final de cada sessão ou de tempos em tempos o paciente deve ler essas anotações e rubricar a ficha. Ter um bom prontuário, nas condições atuais que a odontologia se encontra perante a sociedade, implicará certamente em melhor relacionamento com o pa- ciente, melhor imagem do cirurgião dentista como profissional de saúde com sua visão integral de seu paciente e diminuição da possibilidade de problemas relacionados ao serviço prestado ao paciente, caso haja alguma implicação judicial. Abaixo estão transcritos os artigos pertinentes:

Código de Ética Odontológico

- Artigo 4: "constituem deveres fundamentais dos profissionais inscritos: elaborar as fichas clínicas dos pacientes, conservando-as em arquivos próprios".

Código de Defesa do Consumidor

- Art. 43 - "O consumidor (...) terá acesso às informações existentes em cadastros, fichas, registros e dados pessoais e de consumo arquivados sobre ele, bem como sobre as suas respectivas fontes".

- $\S 2^{\circ}$ - A abertura de cadastro, ficha, registro e dados pessoais e de consumo deverá ser comunicada por escrito ao consumidor, quando não solicitada por ele".

- Art. 72 - "Impedir ou dificultar o acesso do consumidor às informações que sobre ele constem em cadastros, banco de dados, fichas ou registros":

- Pena - Detenção de seis meses a um ano ou multa."

b) Plano de Tratamento: deve ser sempre por escrito. Devem ser colocadas todas as alternativas possíveis para aquele caso. Cada uma com descrição, custos, vantagens e desvantagens e limitações. Expectativas realistas diminuem a tendência a desapontamentos. O paciente escolhe uma das alternativas com auxílio do profissional e assina (recomendação do Código de Defesa do Consumidor, art. 31).

c) Orientações e solicitação de exames: As solicitações de exames complementares devem ser feitas com cópia ou anotadas na ficha clínica sendo rubricadas pelo paciente ou responsável. Todas as orientações (higiene oral, uso dos aparelhos etc) também devem ser feitas por escrito, anotadas na ficha com a rubrica do paciente. Os encaminhamentos devem ser feitos em 2 vias e o recibo deve 
ser assinado pelo paciente ou responsável. No caso de pacientes menores, os pais podem dar uma autorização para que eles mesmos possam assinar os recibos e rubricar as fichas de documentação.

d) Atestados: devem ser feitos com cópia ou anotados na ficha clínica com rubrica do paciente ou responsável. Deve sempre ter uma finalidade específica, não existe "atestado para os devidos fins". Só existem 6 tipos de atestado: escolar, trabalhista, militar, policial, judiciário e esportivo. Os atestados só devem ser fornecidos quando solicitados e devem ser feitos por um período fechado, o repouso deve ser solicitado em horas. Deve-se respeitar o sigilo profissional colocando-se o CID sem descrever o procedimento executado. Esse sigilo é um dever do profissional e um direito do paciente. O Código penal traz alguns artigos relacionados ao fornecimento de atestados:

- Art. 302 - "Dar o médico, no exercício da sua profissão, atestado falso:

Pena - detenção, de 1 (um) mês a 1 (um) ano.

Parágrafo único. Se o crime é cometido com o fim de lucro, aplica-se também uma multa."

- Art. 299 - "Omitir, em documento público ou particular, declaração que dele devia constar, ou nele inserir ou fazer inserir declaração falsa ou diversa da que devia ser escrita, com o fim de prejudicar direito, criar obrigação ou alterar a verdade sobre fato juridicamente relevante:

Pena: reclusão, de 1 (um) a 5 (cinco) anos, e multa, se o documento é público, e reclusão de 1 (um) a 3 (três) anos, e multa, se o documento é particular."

e) Receitas: devem ser manuscritas (próprio punho, à tinta, em português, com letra legível), conter nome e endereço do paciente e o modo de usar a medicação. Pode ser digitada e impressa. O papel receituário pode ser de qualquer cor exceto amarelo. A prescrição de drogas deve ser feita com os nomes genéricos. Deve constar endereço do consultório, data, assinatura e carimbo do profissional com nome e registro no $\mathrm{CRO}$. As receitas devem ser feitas com cópia carbonada ou assina- tura carbonada (quando for impressa), sendo que o paciente deve assinar, na cópia, o recebimento da original.

f) Contrato de prestação de serviços: o contrato é uma manifestação da vontade das partes. Segundo o Código Civil Brasileiro, os contratos podem ser expressos ou tácitos, mas segundo o Código de Defesa do Consumidor, os contratos devem ser escritos, salvo prática anterior. Geralmente os dentistas não gostam de contratos escritos, pois são formais e dão trabalho. Porém eles são muito importantes, pois protegem as partes, caracterizam um acordo de vontades, legitimam a escolha do plano de tratamento, dão concordância em relação ao custo e a forma de pagamento, esclarecem a respeito dos serviços a serem executados (tipo, riscos, limitações etc.) e servem para autorizar a realização do tratamento. Nesses contratos devem constar: diagnóstico, plano de tratamento escolhido, valor e forma de pagamento, prazo de duração do tratamento (início e término estimado), prognóstico, regras às quais o paciente será submetido (faltas, horário, reposição de peças etc.), alguns esclarecimentos a respeito do tratamento (cooperação, cuidados com o aparelho, instruções $\mathrm{HO}$, riscos e limitações etc) e os direitos do paciente e do profissional. O responsável pelo pagamento é quem assina o contrato. Deve-se ter cuidado com pais separados - nem sempre quem tem a guarda ou tutela da criança irá pagar o tratamento. $\mathrm{O}$ contrato deve ter uma redação clara, que não permita interpretação duvidosa. Em relação ao valor orçado, salvo estipulação em contrário, o mesmo terá validade pelo prazo de dez dias, contado do seu recebimento pelo consumidor (paciente). Uma vez aprovada pelo consumidor (paciente), o orçamento obriga os contraentes e somente pode ser alterado mediante livre negociação das partes. E finalmente, os modelos de contratos prontos não são ideais - não daria para contemplar todas as possibilidades. Eles têm que ser adequados a cada situação. A seguir alguns artigos relacionados aos contratos de prestação de serviços: 
Código de Defesa do Consumidor:

- Art. 37: Publicidade enganosa por omissão: quando o fornecedor deixa de informar dados essenciais do produto ou serviço, levando o consumidor a cometer um erro.

- Art. 47: Na dúvida, as cláusulas contratuais serão sempre interpretadas em favor do consumidor.

- Art. 40, § 3: "O consumidor não responde por qualquer ônus ou acréscimos decorrentes da contratação de serviços de terceiros não previsto no orçamento prévio".

- Art. 39 - "É vedado ao fornecedor de produtos ou serviços, dentre outras práticas abusivas:

- IV - prevalecer-se da fraqueza ou ignorância do consumidor, tendo em vista a sua idade, saúde, conhecimento ou condição social, para impingirlhes seus produtos ou serviços".

- Art. 31: "A oferta e apresentação de produtos ou serviços devem assegurar informações corretas, precisas, ostensivas e em língua portuguesa sobre suas características, qualidades, quantidade, composição, preço, garantia, prazos de validade e origem, entre outros dados, bem como sobre os riscos que apresentam à saúde e segurança dos consumidores".

Código de Ética Odontológica:

- Capítulo V seção I, Art. 6: "constitui infração deixar de esclarecer adequadamente os propósitos, riscos, custos e alternativas do tratamento."

g) Cobrança das manutenções mensais: a execução do tratamento ortodôntico com a cobrança somente das manutenções mensais pode ser legal, mas não é ético. A seguir o que diz a legislação:

- Código de Defesa do Consumidor - Art. 30:

"Toda informação ou publicidade, suficientemente precisa, veiculada por qualquer forma ou meio de comunicação com relação a produtos e serviços oferecidos ou apresentados obriga o fornecedor que a fizer veicular ou dela se utilizar e integra o contrato que vier a ser celebrado".

- Código de Ética Odontológica:

Art. 4 - Deveres do profissional inscrito: "abs- ter-se da prática de atos que impliquem mercantilização da odontologia ou sua má conceituação".

Infrações éticas:

Art. 8: "praticar ou permitir que se pratique concorrência desleal".

Art. 10: "oferecer serviços gratuitos a quem possa remunerá-los adequadamente".

Art. 21: "executar e anunciar trabalho gratuito com finalidade de aliciamento".

$\mathrm{E}$ os planos que aliciam pacientes? Podem configurar crime contra a ordem econômica e os responsáveis pelo plano de saúde também podem ser responsabilizados em caso de falha no atendimento do profissional conveniado, conforme diz o Código de Defesa do Consumidor:

- Art. 39: Venda ou operação casada:

- Ocorre quando o fornecedor, para vender produto ou serviço obriga o consumidor a comprar um outro ou quantidades maiores do mesmo.

- Crime contra a ordem econômica (Lei $8.137 / 90$, art. 5, II e III) - pena: detenção de 2 a 5 anos, ou multa.

- Art. $7^{\circ}$, parágrafo único: Responsabilidade solidária:

- A administradora do plano de saúde é responsável por qualquer dano provocado por atendimento deficiente.

A cobrança das manutenções com valores abaixo da VRCC pode constituir uma infração ética se esses valores servirem como forma de divulgação do profissional, ou seja, na prática o profissional pode cobrar o que quiser, porém não pode anunciar valores ou modalidades de pagamento, principalmente se forem abaixo da VRCC (Valores Referenciais para convênios e credenciamentos). Vejamos o que diz o Código de Ética Odontológico:

- Art. 8: Constitui infração ética:

"Praticar ou permitir que se pratique concorrência desleal"

- Art. 11: "cobrar ou receber honorários inferiores ao da Tabela Nacional de Convênios e Credenciamentos ou outra que a substitua, desde 
que aprovada por todas as entidades nacionais de Odontologia".

Em relação ao pagamento mensal o termo mais usado é "manutenções mensais", porém seria melhor usar "parcelas mensais". Ao se fazer o plano de pagamento, preferencialmente não usar a palavra "orçamento". O contrato deve ser sempre feito por escrito, com o valor total do tratamento, o número de parcelas mensais ou até quando serão pagas, o valor de cada uma e a data de vencimento, a forma de reajuste dessas parcelas e a periodicidade. Ele deve também prever a cobrança das parcelas mensais desvinculadas do número de consultas no mês ou então a cobrança por consulta. Deve constar a assinatura do paciente ou responsável pelo pagamento e a do profissional e duas testemunhas. Se houver alguma alteração, deve ser feita por escrito e paciente ou responsável também deve assinar. O Código de Defesa do Consumidor diz que nenhum paciente pode ser submetido a um custo inesperado. $\mathrm{O}$ que estiver escrito e previamente acordado entre as partes terá que ser respeitado durante toda a vigência do mesmo. É interessante constar também no contrato que em caso de inadimplência, o contrato fica rescindido. Nesse caso, o profissional pode fazer a remoção do aparelho e o responsável assina a rescisão do mesmo. Em termos de pagamento, o dentista pode receber cheques pré-datados (lembrar que vencem em seis meses), emitir boletos para pagamento bancário e/ ou promissórias; só não pode emitir duplicatas.

Em relação à forma de reajuste das parcelas mensais, as mesmas podem ser indexadas a qualquer índice do governo, inclusive ao salário mínimo. O que for acordado entre as partes é lei. Não há uma proibição expressa nas relações privadas. Houve uma época na qual o governo tentava evitar associações ao salário mínimo, porém era apenas com o objetivo de evitar a espiral inflacionária. O mais importante é sempre emitir recibo ou nota fiscal com aviso de recebimento na $2^{\mathrm{a}}$ via.

No caso de atrasos no pagamento das parcelas devidas, o tratamento não deve ser interrompido, e na hora da cobrança deve-se tomar muito cuidado. De preferência deve ser feita por um funcionário treinado, sem a presença de outras pessoas por perto. Cabe ao profissional orientar a recepção para que não faça eventuais cobranças na frente de outros pacientes que estiverem na sala de espera. O constrangimento ou a ameaça pode se manifestar, tanto pela força física, quanto pela coação moral e a vítima pode pleitear indenização por danos morais. O Código de Defesa do Consumidor é bastante claro sobre esse tópico:

- Art. 42 - "Na cobrança de débitos, o consumidor inadimplente não será exposto a ridículo nem será submetido a qualquer tipo de constrangimento ou ameaça".

- Art. 71: da pena: crime passível de detenção e multa.

Em relação à interrupção de tratamento, o Código de Ética Odontológico diz o seguinte:

- Constitui infração ética:

- Abandonar paciente, salvo motivo justificável, circunstâncias em que serão conciliados os honorários e indicado substituto.

h) Documentação ortodôntica: a documentação ortodôntica pertence ao paciente, exceto as anotações do profissional, mesmo que ele não tenha pago por isso. Não adianta o profissional querer tomar posse da mesma indevidamente, pois se o paciente pedir em juízo, ele a recebe. Ao final do tratamento o profissional pode devolvê-la ao paciente ou ficar com ela guardada em sua clínica. Se ficar acordado que ficará com o profissional, o paciente pode fazer uma doação por escrito, através de um termo aditivo ao contrato ou simplesmente não levar ao final do tratamento. Se o paciente decidir levá-la embora, o dentista deve lançar essa informação no prontuário. $\mathrm{O}$ paciente assina recibo com inventário da documentação e passa a ser depositário da mesma, com a advertência de que deve preservá-la e apresentá-la quando solicitado, tanto nas consultas de contenção quanto na justiça, se houver necessidade. Caso o profissional deseje, poderá fazer cópia da mesma no todo ou 
em parte antes da devolução para o paciente.

Ao final do tratamento, o paciente deve assinar um recibo numa das vias da solicitação de documentação final. Nessa solicitação deve haver um aviso de que a falta dessa documentação, no prazo marcado, poderá acarretar conseqüências indesejáveis que podem comprometer o resultado do tratamento e que o profissional não será responsável por elas.

Para divulgação de qualquer parte da documentação, seja em aulas, congressos científicos ou publicações de qualquer espécie, é necessária a autorização por escrito do paciente ou responsável, quando menor de 18 anos. Deve-se preservar o direito da imagem.

A documentação ortodôntica é difícil de ser armazenada por longos anos, devido à possibilidade de sua deterioração e por ocupar muito espaço. Em função disso, cada vez mais se fala em documentação digital, onde os dados do paciente são todos armazenados dentro do computador. Porém, algumas pessoas têm contestado sua validade jurídica, baseado na argumentação que um documento para ter força probante deve ter autenticidade e integridade. $\mathrm{E}$ as imagens digitais são passíveis de alterações, que são imperceptíveis ao leigo; só detectáveis através de perícia técnica. Felizmente, a certificação digital desenvolvida inicialmente para órgãos do governo agora é acessível a todos. Tratase de um método de identificação de partes em meio eletrônico, de forma a garantir a autenticidade do documento, sua integridade e, conseqüentemente, dar-lhe validade jurídica. Desta maneira, a justiça brasileira começa a aceitar documentos "virtuais" nas relações entre pessoa física e pessoa jurídica.

Os modelos de gesso talvez sejam os elementos da documentação ortodôntica mais difíceis de serem guardados, pois são frágeis, passíveis de fraturas e com problemas de fungos. Por isso devem ser guardados em bom estado de conservação. A solução, caso não se adote os modelos virtuais, pode ser a confecção de cópias reprográficas data- das e identificadas.

Outra questão que sempre gera dúvidas diz respeito ao tempo no qual a documentação deve ser guardada pelo profissional. As interpretações são variadas e estão diretamente relacionadas ao prazo de prescrição de eventuais processos na justiça, e à esfera na qual o paciente pode reclamar seus direitos. De acordo com o Código Civil, o tempo máximo de armazenamento seria o mesmo para a prescrição, que é de 10 anos:

- Art. 205: "A prescrição ocorre em dez anos, quando a lei não the haja fixado prazo menor".

- Art. 206: "Prescreve:

...

$\S 3^{\circ}$ : Em três anos:

...

V - a pretensão de reparação civil."

E segundo o Código de Defesa do Consumidor, o prazo máximo de armazenamento corresponderia a cinco anos, equivalente ao tempo da prescrição:

- Art. 27 - Prescreve em cinco anos a pretensão à reparação de danos, contados a partir da data do conhecimento do dano e de sua autoria".

i) Atendimento por auxiliares de consultório: muitos profissionais da Ortodontia mantêm em suas clínicas auxiliares para fazer o atendimento de seus pacientes. Essas profissionais podem executar diversas funções dentro da clínica, mas falta uma previsão normativa que dispõe sobre suas atividades. Existem duas resoluções no Conselho Federal de Odontologia, uma para Técnico de Higiene Dental (THD) e outra para Atendente de Consultório Dentário (ACD):

- Res. CFO 185/93, cap. IV: para THD's

- Res. CFO 185/93, cap. V: para ACD’s

Em nenhuma dessas resoluções há previsão de competência para colagem de braquetes e cimentação de bandas, mesmo sendo atos considerados reversíveis ${ }^{2}$.

Desta maneira, para evitar problemas legais, sugere-se que a atuação dos ACD’s fique restrita a procedimentos simples com risco mínimo como, 
por exemplo, a higienização oral. E os THD’s podem executar colagem de braquetes e cimentação de bandas, pois não há proibição formal, desde que seja na presença do Ortodontista. Nesses casos, o paciente deve ser avisado no início do tratamento, por escrito, que seu atendimento eventualmente poderá ser feito por um auxiliar sob a orientação do profissional. Desta maneira, ele terá condições de decidir se mesmo assim irá querer fazer seu tratamento naquela clínica ou se irá procurar alguma outra clínica onde será atendido exclusivamente pelo profissional. Deve-se também ressaltar que no caso de atendimento por auxiliares, se houver algum problema neste atendimento ocorrido sem a presença do ortodontista, o profissional responsável técnico pela clínica poderá ser duplamente responsabilizado.

j) Transferência de pacientes: é muito comum o Ortodontista receber em seu consultório alguns pacientes vindos de outros profissionais, seja para dar continuidade ao tratamento ou para solicitar a remoção do aparelho. Também é comum um paciente de um determinado profissional ser obrigado a mudar de profissional devido à mudança de cidade ou mesmo por razões pessoais. Para regular essas transições, existem algumas regras que facilitam o processo e evitam desentendimentos que podem ir parar na justiça. Em primeiro lugar não é ético remover aparelho colocado por outro profissional sem antes instruir o paciente para que o faça com o mesmo. Sempre solicitar nova documentação antes de remover aparelho ou dar continuidade ao tratamento. Ao transferir um paciente, transferir junto toda a documentação do caso e uma carta explicando os procedimentos executados e expondo os motivos da transferência. $\mathrm{O}$ profissional que recebe o caso deve ter consentimento por escrito do paciente para dar continuidade ao tratamento. Existem modelos de formulários de transferência já prontos, que podem ser muito úteis.

Muitas vezes, o caso transferido vem de um colega que mudou, faleceu ou abandonou o trata- mento e o mesmo está mal conduzido. Como proceder? Será que o profissional é obrigado a atendêlo? Na prática pode-se recusar o tratamento, desde que o paciente tenha outras opções de escolha, se não, será uma falta ética do profissional que recusa o caso. Abaixo estão os artigos do CDC e do CEO que regulam esse tipo de situação:

- Código de Defesa do Consumidor:

Art. 39 - "É vedado ao fornecedor de produtos ou serviços, dentre outras práticas abusivas:

- II - Recusar atendimento às demandas dos consumidores, na exata medida de suas disponibilidades de estoque, e, ainda, de conformidade com os usos e costumes.

- IX - Recusar a venda de bens ou a prestação de serviços, diretamente a quem se disponha a adquiri-los mediante pronto pagamento, ressalvados os casos de intermediação regulados em leis especiais."

- Código de Ética Odontológica:

"Constitui infração ética":

- Deixar de esclarecer adequadamente os propósitos, riscos, custos e alternativas do tratamento.

- Deixar de atender paciente que procure cuidados profissionais em caso de urgência, quando não haja outro cirurgião dentista em condições de fazê-lo.

k) Interrupção do tratamento: A relação profissional-paciente é de natureza contratual, pois há responsabilidades recíprocas. Uma vez iniciado o tratamento, é obrigatório que o profissional leve o caso até o final, ou em qualquer tempo, desde que ambos concordem em acabar o tratamento. Porém, caso seja inevitável uma dispensa, o paciente deve ter a indicação de outro profissional que possa dar continuidade ao caso, ser informado do motivo de tal atitude, ter o fato registrado no histórico clínico, receber assistência até que novo tratamento seja providenciado, receber toda a documentação clínica e assinar recibo.

1) Abandono de tratamento: No caso de abandono do tratamento por parte do paciente, o profissional terá que seguir algumas regras para se 
resguardar contra possíveis problemas legais. Sugere-se que mande até três telegramas (com intervalos de 15 ou 30 dias) com solicitação de cópia ou correspondências registradas com A.R. Caso o paciente já tenha pagado ou tenha ficado devendo algo pode fazer os ajustes financeiros no retorno. Se não retornar e ainda tiver débitos, o profissional pode cobrá-los na justiça.

m) Promessas de resultado: Como já foi dito anteriormente, o tratamento ortodôntico deveria ser visto como um contrato de meio, ou seja, o profissional tem a obrigação de usar todos os meios ao seu alcance, respeitando os limites da ética e da ciência, para conseguir chegar a um resultado favorável no tratamento. Porém, a justiça vê, cada vez mais vendo esta ciência como um contrato de fim, onde o que importa é o resultado final, não considerando aí as variáveis biológicas que podem influenciar neste resultado. Tal posição se deve em parte a um conceito errôneo de venda de "beleza final", consolidado através de material publicitário impróprio, onde o profissional divulga fotos clínicas de casos tratados, "antes" e "depois" do tratamento, e a divulgação de programas que fazem a simulação do resultado de tratamento em computador. Tal conduta por parte de alguns profissionais deveria ser revista, uma vez que se sabe que cada caso é único, com suas particularidades e suas variáveis biológicas. A melhor conduta seria explicitar no contrato de prestação de serviços que o sucesso do tratamento depende de vários fatores e listar quais são esses fatores (crescimento, colaboração no uso dos aparelhos prescritos, condições periodontais etc.).

Deve-se ter muito cuidado com as falsas promessas de resultado. O Código de Defesa do Consumidor prevê punição para a propaganda enganosa feita para captar cliente.

- Art. 37: Sobre a propaganda enganosa:

Contém informação falsa capaz de convencer o consumidor a adquirir um produto ou serviço diferente do que pretendia ou esperava na hora da compra.
- Art. 30 e 67: a propaganda integra o contrato e obriga o fornecedor a cumprir o que foi noticiado.

- Art. 38: as agências de publicidade estão isentas da obrigação de provar a veracidade e correção da informação.

n) Problemas na fase de contenção: Essa fase do tratamento é sabida ser tão importante quanto a fase ativa, pois é conhecida a falta de estabilidade da posição dentária. Os problemas vão desde um simples movimento dentário levando a um apinhamento até uma disfunção da articulação têmporo-mandibular. Sugere-se sempre esclarecer oralmente e por escrito as regras da contenção antes e após o tratamento e marcar consultas periódicas de contenção para poder tomar as medidas necessárias. Cerca de $65,2 \%$ dos pacientes acreditam que os resultados obtidos ao final do tratamento são mantidos pela vida toda ${ }^{11}$. Talvez os próprios ortodontistas tenham uma parcela de culpa quando não esclarecem ao paciente quando acaba a sua responsabilidade sobre o $\mathrm{caso}^{4}$. Nesse ponto o ortodontista deve tomar cuidado, pois a justiça tende a achar que o profissional sempre quer colocar a culpa no paciente quando o tratamento não dá certo.

Com relação às consultas de contenção existem alguns autores que sugerem a desvinculação após algum tempo. Segundo esses autores, os tribunais americanos interpretam que há sempre uma "janela de tempo", na qual o paciente pode iniciar um processo litigioso. Há maneiras de se "parar o relógio", alongando esse tempo de risco legal. Tais condutas incluem a sonegação de informações para o paciente, as informações de que um determinado problema vai melhorar com o tempo e a manutenção indefinida da contenção. A conduta mais apropriada seria destacar ao final do tratamento os pontos positivos e as falhas, como por exemplo, a presença de espaços, possíveis reabsorções radiculares, áreas de descalcificação etc., encaminhando-o para os devidos tratamentos ${ }^{4}$.

Em relação aos encaminhamentos vale ressal- 
tar que é imprescindível selecionar as indicações cuidadosamente. Ao encaminhar, evitar recomendar uma técnica específica de procedimento e pedir sempre para o profissional indicado avaliar a situação. Alguns autores sugerem também que o ortodontista fique de fora do consultório quando o outro especialista tiver atuando, válido aí também para os centros cirúrgicos nos casos de cirurgias ortognáticas.

\section{CONCLUSÃO}

A relação profissional-paciente não é das mais fáceis, mas há várias maneiras do profissional se proteger de eventuais problemas legais. Em suma, poderíamos resumir com alguns conselhos, tais como: manter um prontuário clínico bem elaborado e estar bem documentado, buscar sempre um embasamento científico na literatura, não dar garantias, pois os trabalhos são feitos em bases biológicas com causas incertas e sujeitas a elementos fora do controle do profissional, manter um bom relacionamento com os pacientes, manter uma comunicação franca e honesta, demonstrar interesse e atenção, saber ouvir, alertar constantemente sobre os problemas existentes, ter cuidado nas indicações (cirurgias/implantes), enfim ser prudente sempre. A sociedade e o sistema judiciário não esperam perfeição, apenas esperam um desempenho com um razoável padrão de cuidados profissionais. E devemos lembrar sempre que o diálogo "escrito" é sempre a melhor solução para prevenir problemas.

\section{AGRADECIMENTOS:}

Promotor de Justiça Dr. Diaulas Ribeiro - Promotoria de Defesa dos Usuários dos Serviços de Saúde - PRÓ-VIDA - MPDFT - Brasília/DF.

\title{
Risk management in orthodontic practice - how to avoid legal problems
}

\begin{abstract}
Introduction: The professional relationship between the orthodontist and his patient is very consuming due to the long duration of clinical treatments. Frequently this relationship can be deteriorated causing damages to both sides. Aim: This paper aims to inform the reader, in an accessible language, about the main juridical problems that can involve the orthodontist in his practice, in the field of civil, criminal and labor law. Methodology: This paper draws the outline of professional activity in orthodontics, analyses obligations and rights of both orthodontists and patients and establishes some concepts of risk management that should be incorporated to the clinical practice. Results and conclusion: Besides technically good and scientifically based work, orthodontists should know how to avoid legal problems. This paper can be an important tool for the establishment of a new clinical and administrative routine that can be safer as far as juridical aspect is concerned.
\end{abstract}

Key words: Orthodontics. Legal problems. Risk management. 


\section{REFERÊNCIAS}

1. CAPELOZZA FILHO, L.; PETRELLI, N. E. Normas gerais para reger as relações de trabalho dos ortodontistas e seus pacientes: uma sugestão para uma necessidade inadiável. Ortodontia (SPO), São Paulo, v. 26, n. 1, p. 87-97, jan./abr. 1993.

2. FRANÇA, B. S. Aspectos legais na Ortodontia. Entrevista. Rev. Clin. Ortodon. Dental Press, Maringá, v. 1, n. 2, p. 5-8, abr./maio 2002.

3. GALVÃO, M.F. Aspectos legais da biossegurança em Odontologia. Revista CRO-DF, Brasília-DF, v.1, n. 3, p. 17-19, mar. 2000.

4. JERROLD, L. It's not my job. Am. J. Orthod. Dentofacial Orthop., St. Louis, v. 110, no. 4, p. 454-455. Oct. 1996.

5. KOUBIK, R.; FERES, M. A. L. Aspectos legais da Ortodontia. Ortodontia (SPO), São Paulo, 28, n. 2, p. 64-70, maio/ ago. 1995.

6. MACHEN, D. E. Diagnosis/root resorption/progress monitoring. Am. J. Orthod. Dentofacial Orthop., St. Louis, v. 95. no. 3, p. 267-268, Mar. 1989.
7. MACHEN, D. E. Periodontal disease in orthodontic practice. Am. J. Orthod. Dentofacial Orthop., St. Louis, 95, no. 5, p. 445-447, May 1989.

8. MACHEN, D. E. The doctor's deposition. Am. J. Orthod. Dentofacial Orthop., St. Louis, v. 96, no. 4, p. 356-358, Oct.1989.

9. MACHEN, D. E. On legal issues in orthodontics. J. Clin. Orthod., Boulder, v. 26, no. 6, p. 347-353, June 1992.

10. PETRELLI, N.E. Aspectos éticos e legais em Ortodontia. Rev. Dental Press Ortodon. Ortop. Facial, v. 3, n. 5, p. 6-10, set./out. 1998.

11. PINZAN, A.; VARGAS NETO, J.; JANSON, G. R. P. O paciente ortodôntico quanto ao seu grau de informação e motivação, e suas expectativas acerca do tratamento. Ortodontia (SPO), v. 30, n.3, p. 40-44, set./out 1997.

12. TERRA, M. S.; MAJOLO, M. S.; CARILLO, V. B. Responsabilidade profissional, ética e o paciente em Ortodontia. Ortodontia (SPO). São Paulo, v. 33, n. 3, p. 74-85, set./dez. 2000.
Endereço para correspondência

Ricardo Machado Cruz

SHIS QI 09/11, Bloco L, sala 101, Lago Sul

CEP: 71625-210 - Brasília/DF

E-mail: ricardomcruz@uol.com.br 